\title{
Study on the Erosion of Screen Pipe Caused by Sand-Laden Slurry
}

\author{
Hualin Liao*,*, Lin Dong*, Jilei Niu*, Peng Ji**, Bing Gu** and Lei Xu** \\ *School of Petroleum Engineering, China University of Petroleum (East China), Qingdao Shandong Prov. 266580; State Key Laboratory of \\ Offshore Oil Exploitation, Beijing 100028, China \\ **Branch Company of Tianjin, Offshore Oil Engineering Company Limited, CNPC, Tianjin \\ *Corresponding Author: liaohualin2003@126.com. (H. Liao)
}

Submitted: 20/11/2019

Revised: $\quad 12 / 03 / 2020$

Accepted: 25/03/2020

\begin{abstract}
Screening is one of the main filtration and separation methods for unconsolidated sandstone reservoirs, and the problem of failure of sand control screen, encountered by some sand control wells in early production phase, gives rise to serious sand production in the shaft and influences normal production in the oilfield. In order to analyze the reason for screen failure in sand control wells and the detailed mechanism of the short service cycle of sand control screens, this paper proposes an experimental device, which can simulate sand screen erosion by the sand-laden slurry under underground working conditions and studies the influence of screen type, salinity, sand particle size, sandladen concentration, erosive angle, and other factors on the degree of erosion of screen filtering medium. Based upon experimental results, the current study establishes a model for predicting the service-life of sand control screens. The results showed that the jet velocity, sand-laden concentration, sand particle size, erosive angle, and other factors exhibited an obvious influence on the erosion of screen, while the salinity of formation water exerted an insignificant influence. Under the same conditions, different types of screens presented relatively significant differences in antierosion performance, whereas the anti-erosion performance of the stars screen was found to be superior to that of the metal mesh screen. The results provide some basis for selecting sand control methods, offering guidance about the production systems and predicting the service-life of screens.
\end{abstract}

Keywords: Sand control; Screen completion; Erosive failure; Prediction model.

\section{INTRODUCTION}

Sand screen filtration is currently the most common separation method, and the service-life of a screen has a direct influence on the productivity and efficiency of oil and water wells. Generally, plugging, erosion, corrosion, stress change, and other factors can all lead to the failure of screen (Mahmoud and Penny, 2000; Furui et al., 2011; Arabnejad et al., 2015; Dong et al., 2016, 2017). In the process of oilfield production, if the sand control methods adopt sand control by an independent screen or if the gravel packing is nonuniform, the sand screen will be directly subjected to impact by sand-laden slurry, whereas the formation sand-laden slurry will either erode the sand screen or even result in the failure of screen (Lau et al., 2004; Kanj and Abousleiman, 2007), as shown in Fig. 1. With regards to the problem of screen failure, previous studies (Jackson and Gundemoni, 2016; Islam and Farhat, 2017) claimed that the erosive wear and failure of metal screens under high temperature, high pressure, and corrosion conditions are related to underground fluid velocity, underground acid environment, screen plugging, and other factors and that a corrosive environment aggravates the failure of a screen. A previous study (Hamid and Ali, 1997; Liu et al., 2009; Gillespie et al., 2009; Gillespie and Jones, 2009) investigated the erosive wear of slotted screens by sand-laden crude oil and 
concluded that the erosion rate of the slotted screens was mainly influenced by sand-laden slurry velocity, sand-laden slurry concentration, sand particle size, and erosive angle. Another study (Cameron and Jones, 2007) reported the influence of different fluid types, flow velocities, sand contents, and particle sizes on the failure of sand screen through experimental and theoretical analyses and proposed a model for predicting the time of failure of the screen. Based on the experimental results, some researchers (Navaira et al., 2009; Svela et al., 2009; Tovar and Zheng, 2011) proposed a method for positioning screen zones with erosion hazards and, based upon different sand control methods, came up with a method for judging the screen failure under different environmental conditions. The same authors reported that the change in flow channel and flow pattern by screen and annulus plugging constituted an important factor for the failure of a screen. Some previous works (Zamberi and Shaffee, 2014; Mnhmoud and Ali., 2015; Sidek and Lian, 2017) focused on the problem of screen failure and, based on experimental work and numerical simulations, suggested that the erosion of screen by sand-laden slurry can be reduced by measures, including introduction of ceramic screens, controlling of the production speed, conducting sand control management, and using a flow divider. In short, there are numerous reasons and factors that may contribute to the failure of a sand screen.
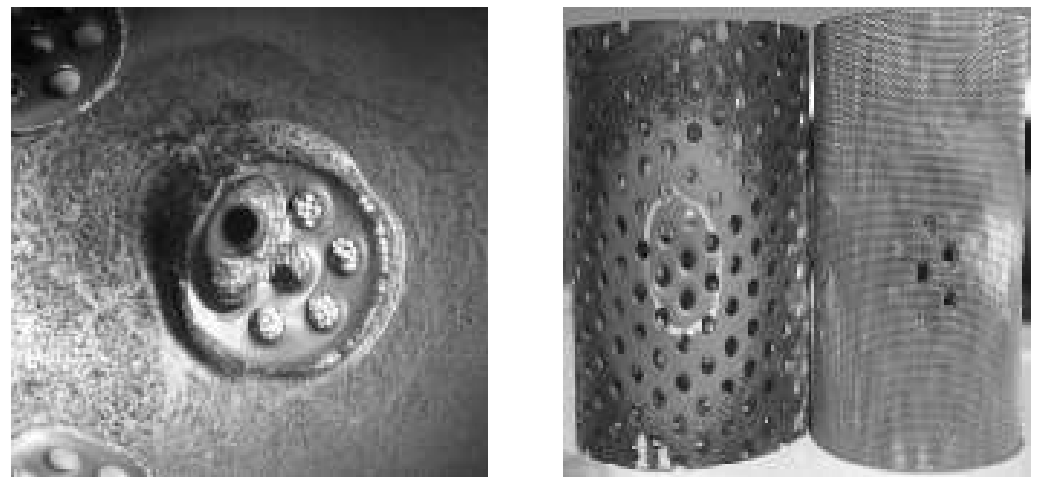

Fig. 1. Erosion of screen filtering media (Tovar et al., 2011).

As an effective mechanical sand control method, the star screen is widely used to support the wellbore and prevent the sand production (Gao et al., 2017; Chen et al., 2019). In many oilfields of China, however, a water source well experienced the puncture failure of a screen several months after the tripping-in, thus giving rise to serious sand production in the shaft, as shown in Table 1. Based on the failure characteristics of the screen and analysis of sanding problem, the failure of star screen is caused by local fluid erosion resulting from nonuniform blockage of sand retaining medium.

Table 1. The failure and characteristics of star screen.

\begin{tabular}{|c|c|c|c|c|c|c|}
\hline $\begin{array}{c}\text { Screen } \\
\text { No. }\end{array}$ & Area & Well No. & Screen type & $\begin{array}{c}\text { Accuracy, } \\
(\boldsymbol{\mu m})\end{array}$ & $\begin{array}{c}\text { Sand } \\
\text { production, } \\
(\text { Yes/No) }\end{array}$ & $\begin{array}{c}\text { effective period } \\
\text { of sand control, } \\
(\text { Month) }\end{array}$ \\
\hline 1 & Bonan & BZ28-2S-A38w & 7"Strar screen & 100 & Yes & 5 \\
\hline 2 & Liaodong & JZ25-1S-A20W & 7"Strar screen & 120 & Yes & 3 \\
\hline 3 & Liaodong & JZ25-1-A16 & 7"Strar screen & 150 & Yes & 6.5 \\
\hline 4 & Boxi & QK17-3-P08 & 4-1/2"Strar screen & 150 & Yes & 5 \\
\hline 5 & Boxi & QK17-3-P08 & 6-5/6" Star screen & 120 & Yes & 0.5 \\
\hline
\end{tabular}


For the purposes of identifying the reasons of sand screen failure under simplified sand control by casing perforation in the water source wells of offshore oilfields and clarifying the internal mechanism of the short sand control cycle, this paper proposes an experimental device, which can simulate sand screen erosion and can experimentally study the influence of sand-laden slurry velocity, particle size, sand-laden concentration, and other factors on the erosive failure time of the screen filtering medium for different types of screens (considering formation water salinity). The study also establishes a model for predicting the service-life of different types of screens, aiming to provide some basis for selecting sand control methods, determining production systems, and predicting screen service-life.

\section{EXPERIMENTAL SETUP}

According to the failure characteristics of screen filtering media for water source wells extracted from underground, it is opined that the sand-laden slurry flowing at a certain velocity constitutes the primary reason for the erosive wear and subsequent failure of screens. Based on the generation method of abrasive jet (Narayanan et al., 2013) and the micro-cutting model for flexible material erosion (Finnie I, 1960,1995), this paper proposes an experimental device, which can simulate screen erosion by sand-laden slurry, as shown in Fig. 2. The device mainly consists of a sand injector, a flow stabilizer, a sand regulator, a screen sample-holding device, a collection box, a frame, and a nozzle. When passing through the sand injector, the high-pressure water coming out of the high-pressure pump forms a high-velocity water jet. The sand injector adopts the formation principle of after-mixing abrasive jet to create both a certain degree of vacuum inside the injector's mixing chamber and a pressure gradient between the sand box and the mixing chamber. The simulated formation sand enters the mixing chamber under the combined action of dead weight and pressure differential, blends with the high-velocity fluid, and forms the sand-laden slurry having a certain flow velocity. The flow-stabilizer is used to regulate and slow down the sand-laden slurry, which is sprayed out through the nozzle. When it acts on the screen sample, it can simulate screen erosion by the sand-laden slurry in the casing's perforation tunnels. The concentration of sand-laden slurry can be realized through the aperture of sand regulator's sand producing opening, which is then weighed and calibrated using an electronic meter. The jet velocity of the sand-laden slurry is determined using the flow rate and nozzle diameter, whereas low-velocity sand-laden slurry is modulated using an additional flow stabilizer and three-stage nozzle. The sample-holding device is mainly used to fix the sample and adjust the angle of screen erosion by sand-laden slurry and its jet distance. The experiment used two types of screens pipes named as stars screen and metal mesh screen as shown in Fig. 3 and Table 2.

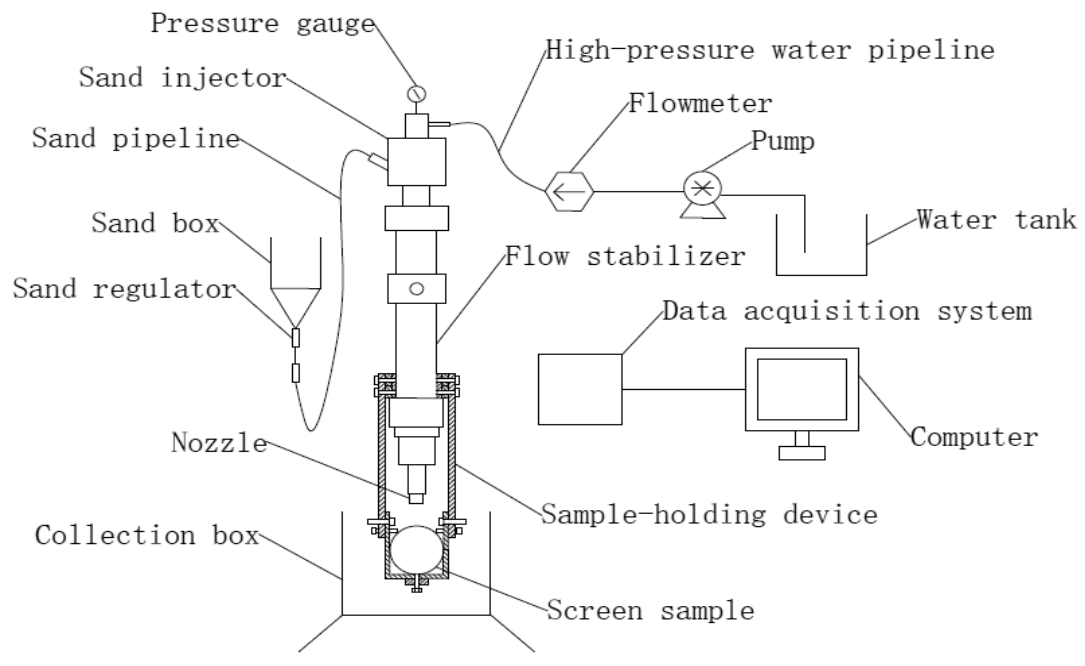

Fig. 2. Schematic of the experimental device. 


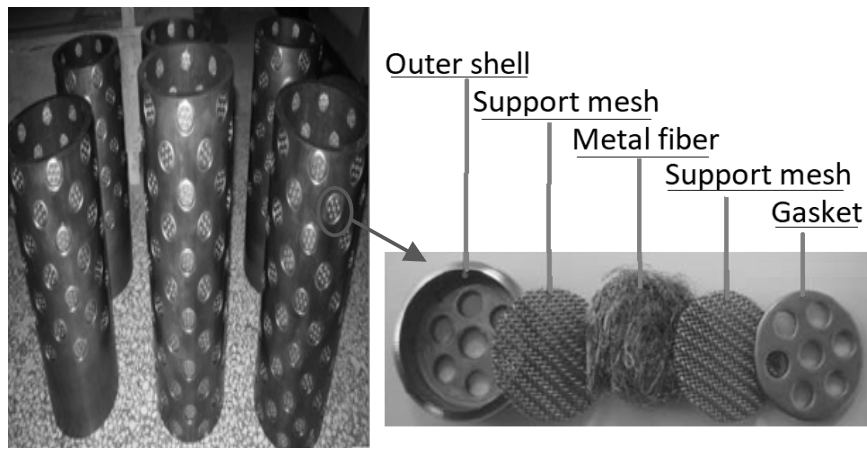

(a) Stars screen

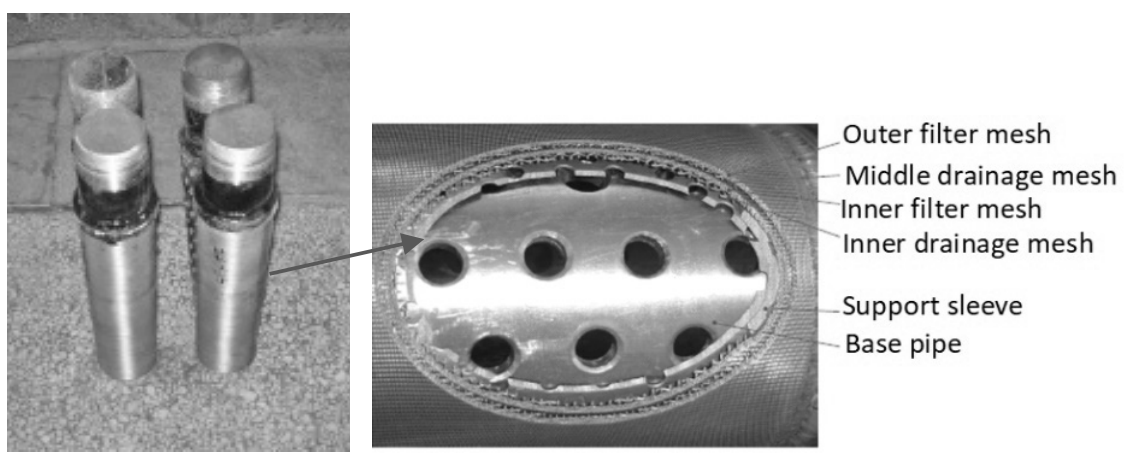

(b) Metal mesh screen

Fig. 3. Screen samples used in the current work.

Table 2. Technical parameters of the screen pipes.

\begin{tabular}{|c|c|c|c|}
\hline Type & I.D, $\mathbf{m m}$ & O.D, $\mathbf{~ m m}$ & Filter precision, $\boldsymbol{\mu m}$ \\
\hline Stars screen & 124.26 & 159.04 & 150 \\
\hline Metal mesh screen & 124.26 & 158 & 150 \\
\hline
\end{tabular}

The experimental parameters mainly included the sand injector's working pressure ps, displacement Q, sand-laden depth w, nozzle diameter $\mathrm{d}$, jet distance $\mathrm{L}$, and erosive angle $\alpha$. The sand injector's working pressure ps was set to be $18 \mathrm{MPa}$, and the average displacement $\mathrm{Q}$ had the value of $12.85 \mathrm{~L} / \mathrm{min}$ for the experiments. The nozzle diameter was determined according to the flow velocity and the displacement, whereas various flow velocities corresponded to different nozzle diameters. The nozzle diameter $d$ varies subsequently through values of $1.3 \mathrm{~mm}, 1.5 \mathrm{~mm}, 3.7 \mathrm{~mm}, 5.2$ $\mathrm{mm}$, and $7.4 \mathrm{~mm}$. The sand-laden concentration $w$ was determined according to the flow rate, which was regulated and calibrated using the sand regulator. Five types of quartz sands are chosen in the erosion experiment as the solid particles with middle size $\mathrm{D}_{50}$ of $100 \mu \mathrm{m}, 150 \mu \mathrm{m}, 200 \mu \mathrm{m}, 300 \mu \mathrm{m}$, and $400 \mu \mathrm{m}$ as shown in Fig. 4 with grain size distributions. The sand roundness is about 0.7 and sphericity is about 0.68 . Specific gravity is 2.67 . The jet distance L referred to the distance from nozzle outlet to the sample (jet spraying point) and was set to be $10 \mathrm{~mm}$ in the experiments. The erosive angle referred to the angle between the jet direction and the sample (tangential plane of the spraying point) and was uniformly set to be $60^{\circ}$ in the experiments. The jet distance and erosive angle are shown in Fig. 5 . 


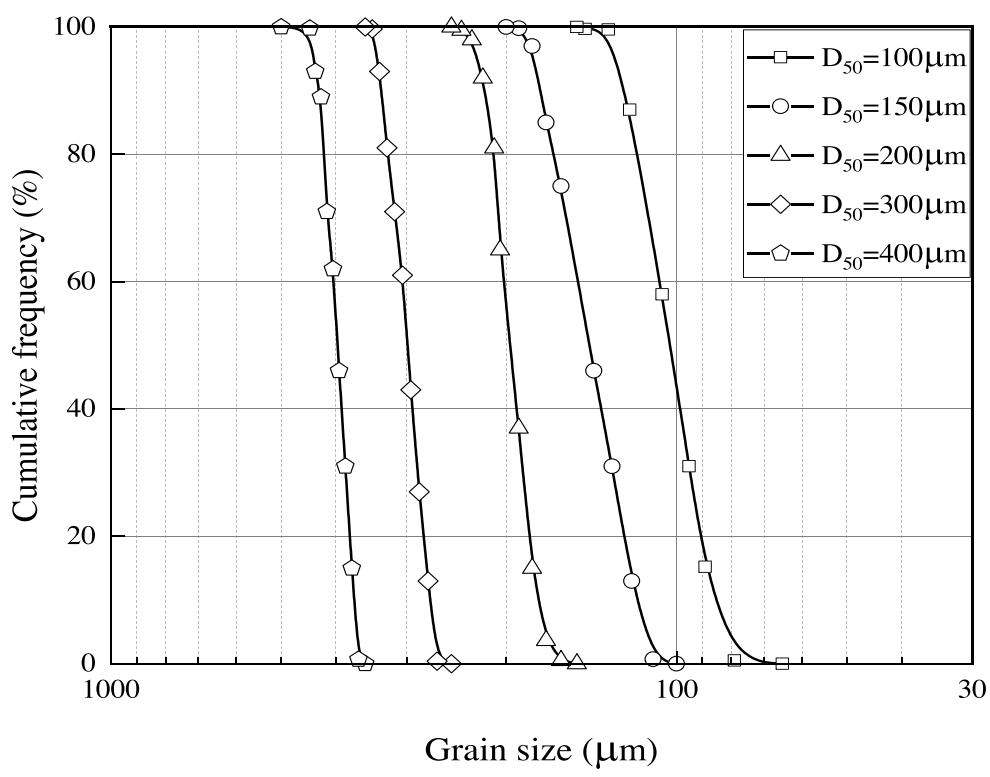

Fig. 4. Grain size distributions.

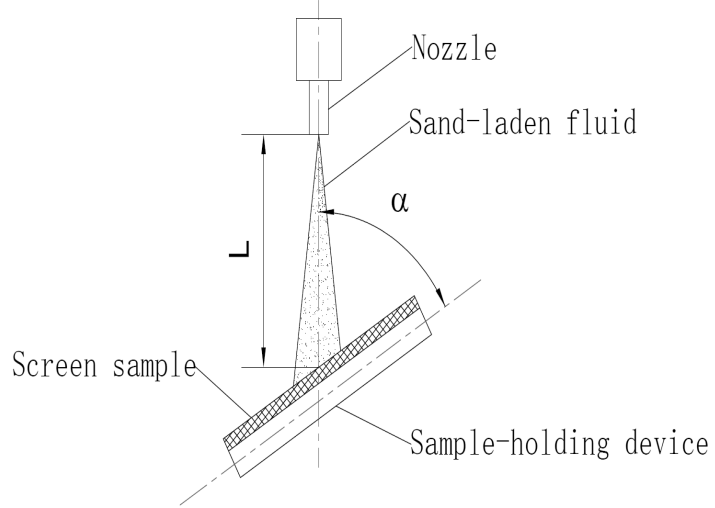

Fig. 5. Schematic of the jet distance and erosive angle.

The experiments were conducted based upon the following procedure.

1) The high-pressure water pipeline was properly connected.

2) The screen sample was installed, both the angle and the jet distance were adjusted, and the collection box was connected (see Fig. 6).

3) The sand production was calibrated according to concentration, and the prepared formation sand was added to the sand box.

4) The high-pressure pump was started, which regulated both the pressure and displacement.

5) The sand pipeline was connected to the sand box, and the timer for the addition of sand was started. This way, the erosion experiment was conducted.

6) The sand pipeline was disconnected from the sand box. The timer for the addition of sand was stopped. The pressure was released. The pump was stopped to suspend the erosion, and the erosive failure of the screen samples was observed. 
7) In case there is no erosive failure, the experiment was continued according to Steps 4 - 5, and the time was adjusted accordingly.

8) The pressure was released, and the high-pressure pump was stopped. The sample was observed (when the screen sample exposes its bottom mesh and inner tube or baseplate, it means that the screen has been punctured and the experiment is over). Each set of experiments was repeated at least three times.

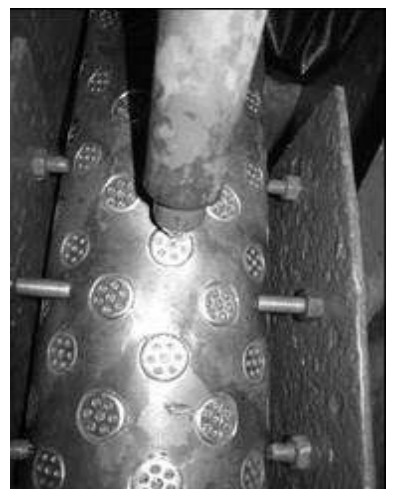

Fig. 6. Installation of the sample.

\section{RESULTS AND DISCUSSION}

\section{Influence of jet velocity on the anti-erosion performance of sand screen}

After maintaining the concentration of sand-laden slurry at $1.0 \%$ and the average sand particle size of $200 \mu \mathrm{m}$, the jet velocity of the sand-laden slurry was subsequently varied through the values of 30,20,15, 10, and $5 \mathrm{~m} / \mathrm{s}$ to study its influence on the erosion failure of screen samples. The erosive failure of the two sand screen samples is shown in Fig. 7-9. Fig. 7 depicts the erosion characteristics of the sand-retaining media of the metal mesh at the flow velocity of $5 \mathrm{~m} / \mathrm{s}$. After erosion for $45 \mathrm{~min}$, the first thin mesh layer was punctured. The first thick mesh layer was thinned, while the second thin mesh layer was partially eroded. After erosion for $70 \mathrm{~min}$, both the first thick mesh layer and the second thin mesh layer were punctured, though the horizontal thread of the second thick mesh layer survived. After erosion for $75 \mathrm{~min}$, the baseplate showed bright, white traces, suggesting that the screen sand-retaining media were basically punctured. Under different jet velocities, the shapes of the metal mesh tunnels were similar, though the aperture decreased with the increase in fluid velocity. At the velocity of $5 \mathrm{~m} / \mathrm{s}$, the minimum aperture was about 5.0 $\mathrm{mm}$. At the velocity of $30 \mathrm{~m} / \mathrm{s}$, the minimum aperture was about $2.5 \mathrm{~mm}$. Fig. 8 depicts the erosion characteristics of the filtering media of the stars screen under five different velocities. The filtering media were metal cotton, and the perforating sites were uniformly distributed small tunnels having the diameter of $2.0 \mathrm{~mm}$.

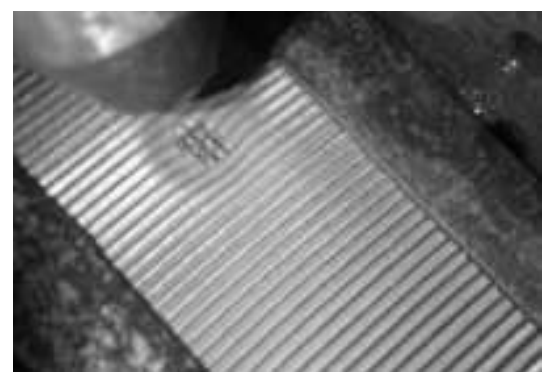

a. Erosion after 45 min

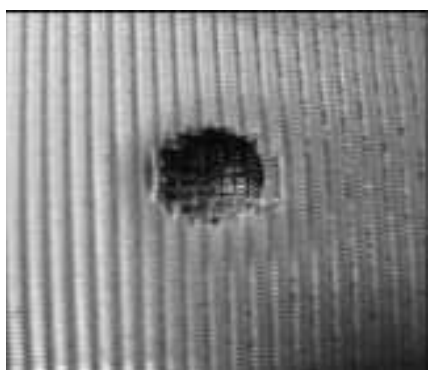

b. Erosion after $70 \mathrm{~min}$

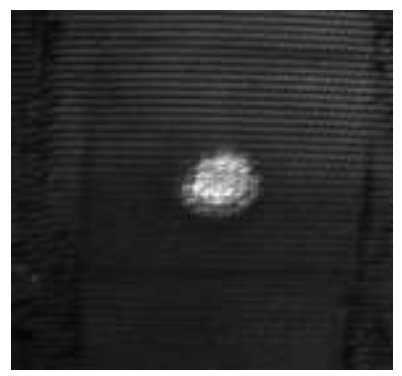

c. Erosion after $75 \mathrm{~min}$

Fig. 7. Erosion characteristics of the metal mesh screen at different time intervals (flow velocity was $5 \mathrm{~m} / \mathrm{s}$ in all three cases). 


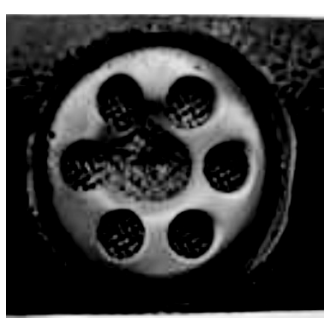

a. Flow velocity of $5 \mathrm{~m} / \mathrm{s}$

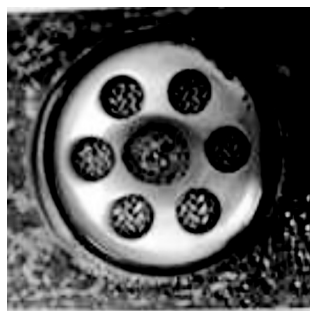

b. Flow velocity of $10 \mathrm{~m} / \mathrm{s}$

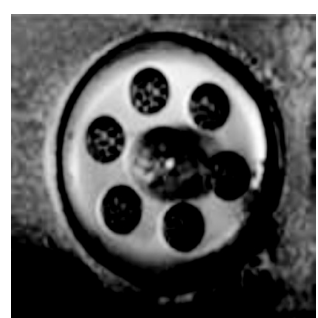

c. Flow velocity of $15 \mathrm{~m} / \mathrm{s}$

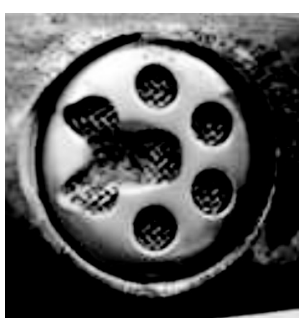

d. Flow velocity of $20 \mathrm{~m} / \mathrm{s}$

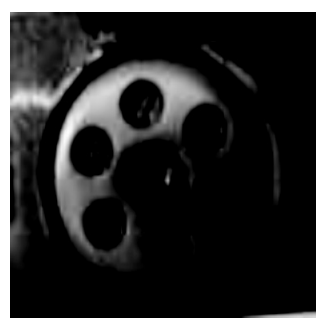

e. Flow velocity of $30 \mathrm{~m} / \mathrm{s}$

Fig. 8. Stars screen erosion under different jet velocities.

Fig. 9 shows the changes in two screen samples with the flow velocity of the sand-laden slurry during erosive puncture time. Each set of experiments was repeated three times, and scatter bars indicated the maximum errors. Under various degrees of screen erosion, with the increase in flow velocity, the erosive failure time of the screens quickly shortened. When the flow velocity increased to a certain level, the influence of increase in flow velocity on erosion weakened to some extent, suggesting that it took some time for the sand-laden slurry to erode the screen sandretaining media and that the sand-laden slurry would cause serious erosive failure to the screen sand-retaining media only when it had reached a certain critical velocity.

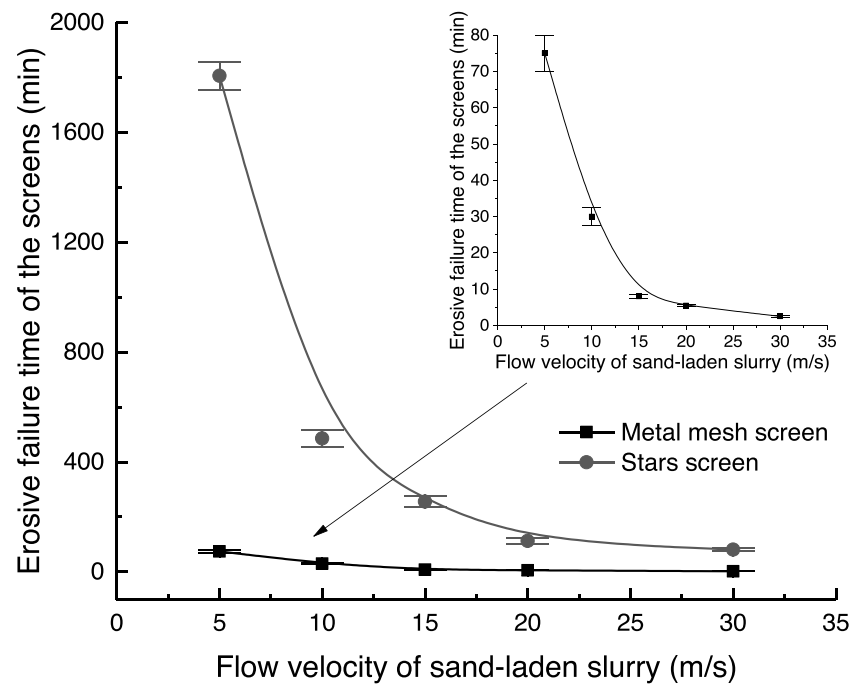

Fig. 9. Erosive puncture times of screens under different flow velocities. 


\section{Influence of the sand-laden slurry's concentration on the anti-erosion performance of sand screen samples}

After setting the flow velocity at $5 \mathrm{~m} / \mathrm{s}$ and the average sand particle size at $200 \mu \mathrm{m}$, the concentration of sandladen slurry (mass percentages) was subsequently varied through the values of $0.5 \%, 1.0 \%, 1.5 \%, 2.0 \%$, and $2.5 \%$ to study its effect on the erosive failure of the screens. The results are presented in Fig. $10-12$.

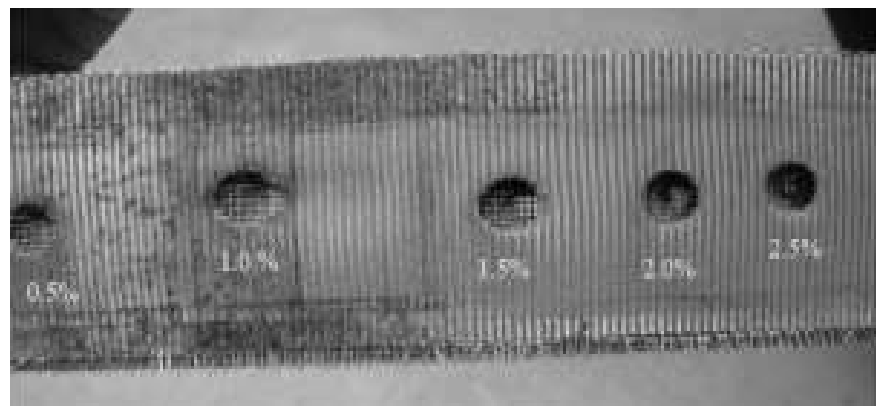

Fig. 10. Erosion of metal mesh screen under different sand-laden concentrations.
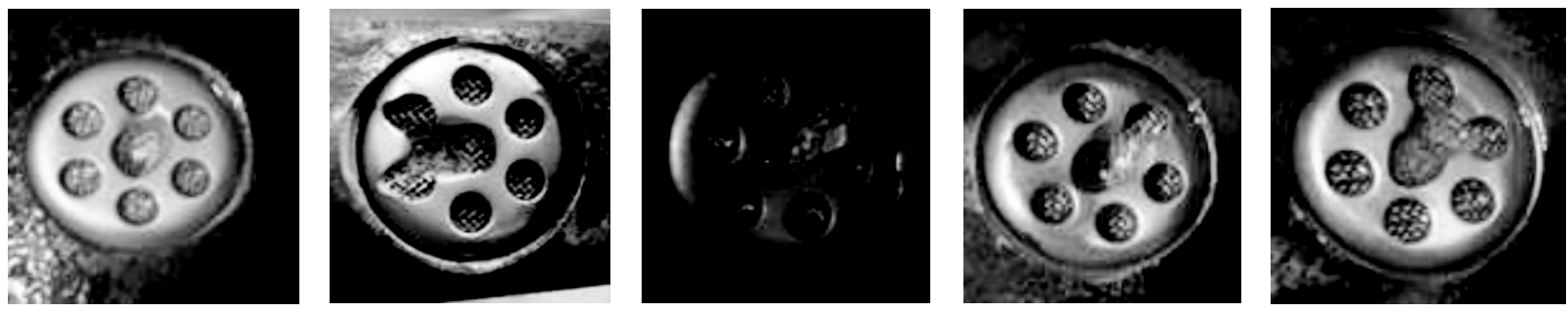

Concentration of $0.5 \%$

Concentration of $1.0 \%$ Concentration of $1.5 \%$

Concentration of $2.0 \%$

Concentration of $2.5 \%$

Fig. 11. Erosion of star screen under different sand-laden concentrations.

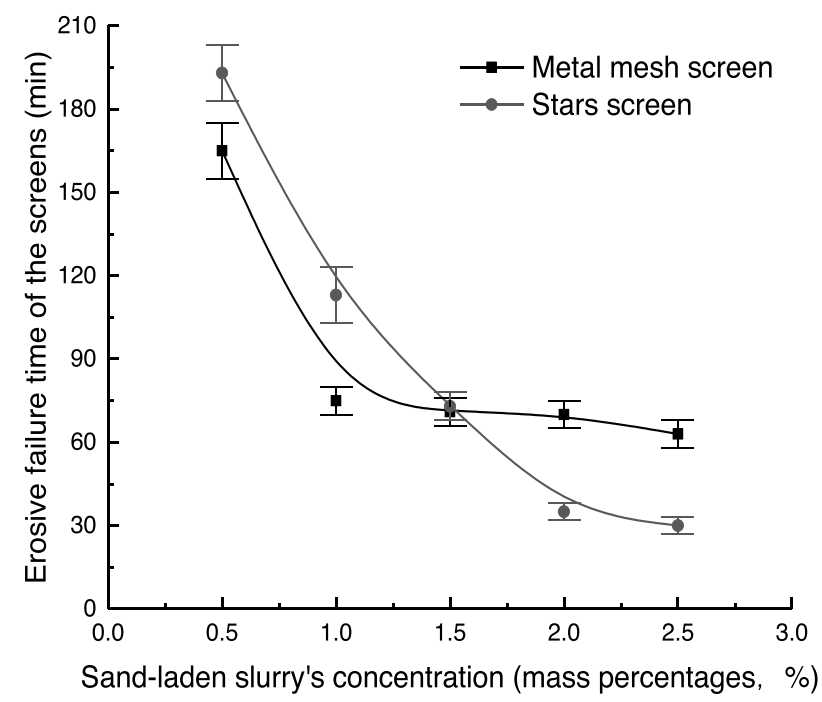

Fig. 12. Comparison of erosive puncture times between the two screen samples under different sand-laden concentrations. 
For the metal mesh screen, with the increase in the concentration of sand-laden slurry, the erosive puncture time of the screen shortened. When the concentration of sand-laden slurry was relatively high, the amplitude of change in the erosive failure time declined. For the stars screen, under the concentrations of $0.5 \%$ and $1.0 \%$ of the sand-laden slurry, the erosive failure times were almost similar to each other. When the concentration of sand-laden slurry increased to $1.5 \%$, the erosive puncture time of the screen was significantly shortened. When the concentration value was further increased, the erosive puncture time declined, though the amplitude of the change dropped significantly.

The concentration of the sand-laden slurry exerted a significant influence on the erosion of metal mesh screen. The higher the concentration, the more serious the erosive failure. However, when the concentration of sand-laden slurry increased to a certain extent, its influence on the erosive failure of the screen samples weakened. Therefore, it was concluded that the metal mesh screen had a relatively low sensitivity to fluids with a medium-to-high sand-laden concentration (above 1.0\%) and that, with the increase in the concentration of sand-laden slurry, the erosion time first decreased and then further decreased with a slower rate. The stars screen had a relatively low sensitivity to fluids with low concentrations $(0.5 \%, 1.0 \%)$ of sand-laden slurry, and, with the increase in sand-laden concentration, the erosion time first showed little change and then was significantly shortened.

\section{Influence of the sand particle size on the anti-erosion performance of sand screen samples}

After setting the flow velocity at $5 \mathrm{~m} / \mathrm{s}$ and the sand-laden slurry's concentration at $1.0 \%$, the sand particle size was varied through the values of $100,150,200,300$, and $400 \mu \mathrm{m}$ to study its effect on the erosive failure of the screens. The results are shown in Fig. 13. The results showed that the sand particle size exerted a relatively significant influence on the erosion of screens. With the increase in sand particle size, the erosion time first decreased and then increased. When the sand particle size was $200 \mu \mathrm{m}$, the erosion time of the metal mesh screen became the shortest. For the stars screen, the sand particle size exerted a relatively significant influence on the erosion of the screen, and the erosion time decreased with the increase in sand particle size. When the sand particle size was $400 \mu \mathrm{m}$, the erosion time of the stars screen became the shortest. As indicated by the analysis on the cutting mechanism of abrasive jet and the characteristics of the perforating sites during the erosion of screen, the erosion of screen sand-retaining media by sandladen slurry was primarily the erosion of screen by sand particles. When the sand-laden slurry impacts the materials at a high velocity, the erosion of material surface is in fact a failure, and the wear of material surface is caused by the high-frequency impact exerted by numerous abrasive particles having high-velocity motion in the fluid. During the motion of abrasive particles, the material surface experiences a horizontal plastic flow at the contact points and cuts out a certain number of micro-volume materials. The erosion is the result of combined action of the deformation wear with a certain angular impact and the horizontal micro-cutting wear in the surface contact with the metal wire material passing through the mesh. When the sand particle size was smaller than the sand-retaining precision of the screen, some sand particles could pass through the mesh woven by the metal wire after impacting the screen. In this case, the horizontal micro-cutting wear plays the dominant role. With the increase in particle size, the sand particles passing through the filtering media are reduced, and the micro-cutting wear is weakened, which is accompanied by the enhancement of the deformation wear caused by the angular impact. Under such experimental conditions, when average particle size was $200 \mu \mathrm{m}$, both these actions played their respective roles, so that the erosive puncture time of the metal mesh screen becomes relatively short. For the stars screen, its filtering media were similar to the metal cotton and had a buffering action for the sand particles having high-velocity impact. Therefore, the micro-cutting wear caused by the sand particles passing through the mesh was relatively weak, and its erosion was primarily the deformation wear incurred by the angular impact. With the increase in sand particle size, the kinetic energy under the same velocity increased, and the erosion of screen was intensified, due to which its impact failure time was shortened. 


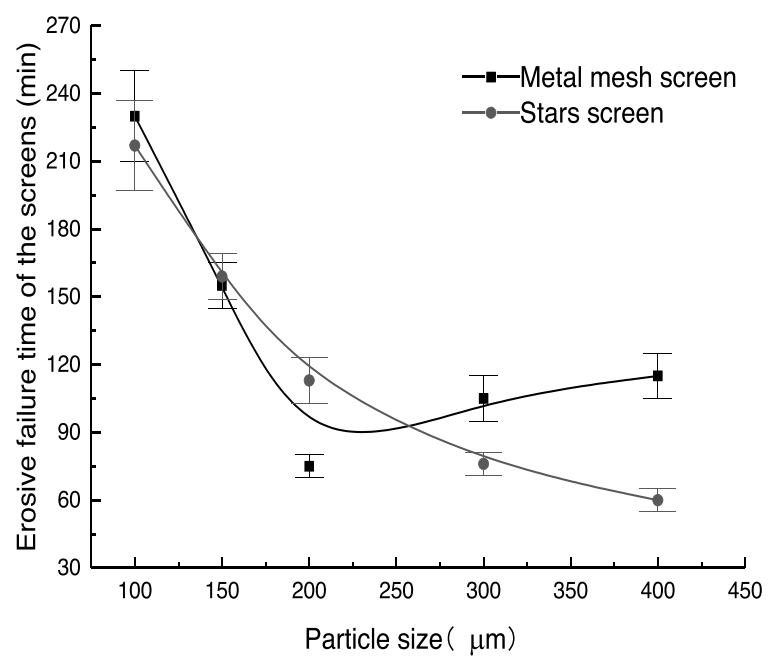

Fig. 13. Comparison of erosive puncture times between the two screen samples under different sand particle sizes.

\section{Model for predicting the erosive failure of screens}

Taking into account the service environment of screens, the conditions under which the screen failure occurs, and the performance of screen materials, if a model can be established for predicting the erosive failure of screens, then screen's erosion behavior, failure phenomenon, and sand-retaining failure time can be explained or predicted. Therefore, such a model can provide the basis for selecting the field sand control methods, choosing the screen materials, and determining the production systems. The existing prediction models for screen failures are mainly based on the erosion experimental data on a certain type of screens. In addition, depending on their purposes, the models can be classified into two types. The first type relates to the models for predicting the erosive wear rate of screens and can be used to analyze the relations between the wear rate of a screen with the flow velocity, sand particle size, sand-laden concentration, and erosive angle. For instance, based on experiments, a previous study (Liu et al, 2007) analyzed the influence of sand-laden crude oil's flow velocity, sand-laden slurry's concentration, sand particle size, and erosive angle on the erosion rate of sand-control slotted screens and established a mathematical model for the erosive wear rate of slotted screens.

$$
Q=5.3961 c^{2.3}\left[1-\left(\frac{0.134}{d}\right)^{2 / 3}\right]^{2} v^{2.355} \sin ^{2} \alpha
$$

where $Q$ represents the slotted screen's erosive wear rate, $g / h ; c$ represents the concentration of sand-laden slurry, $\% ; d$ represents the formation sand particle diameter, $m m ; v$ represents the fluid velocity, $\mathrm{m} / \mathrm{s}$; and $\alpha$ represents the erosive angle, $\stackrel{\circ}{\text {. }}$

The second type relates to the prediction models for screen failure time, and relevant prediction methods are created by analyzing the influencing factors related to screen's failure time. For instance, a previous study (Cameron and Jones, 2007) analyzed the relations of screen's failure time with fluid properties, flow rate, solid load, and solid particle properties and established a model for predicting the erosive failure time of expandable slotted screens under simplified sand-control condition of perforated casing completion.

$$
t_{s l}=4 M_{\text {loss limit }}\left(k \cdot \pi \cdot d_{\text {perf }}^{2} \cdot v_{a} \cdot k_{s f} \cdot \rho_{s} \cdot N \cdot \frac{m_{\text {metalloss }}}{m_{\text {particles }}}\right)^{-1}
$$

where $t_{s l}$ represents the predicted wear failure time, $s ; M_{\text {losslimit }}$ represents the maximum mass loss, $g$; $k$ represents the unitary transformation constant; $d_{p e r f}$ represents the perforation tunnel diameter, $\mathrm{cm} ; v_{a}$ represents the tunnel outlet 
flow velocity, $\mathrm{cm} / \mathrm{s} ; k_{s f}$ represents the particle shape factor; $\rho_{s}$ represents the sand particles' specific gravity, $\mathrm{g} / \mathrm{cm}^{3} ; N$ represents the particle volume fraction; $m_{\text {metalloss }}$ represents the screen mass loss in the experimental process, $g$; and $m_{\text {particles }}$ represents the mass of particles passing through a screen, $g$.

Some of the parameters for Equations (1) and (2) were obtained from the experimental work, though they are difficult to be acquired in actual production. According to the results of experiments, fluid velocity, sand-laden slurry's concentration, and particle size exerted a relatively significant influence on the erosive puncture time of screens, while the influence of the salinity of formation water on the erosive failure time of the stars screen was relatively insignificant. As indicated by the analysis on the correlations between the erosive puncture time and various other factors, the change in erosive failure time of the stars screen with fluid velocity, sand-laden slurry's concentration, and particle size conformed to a power function. Based on the massive data measured in the experiments, the curve fitting method was used to establish the relationships of erosive puncture time with the fluid velocity, sand-laden slurry's concentration, and particle size and is given by Equation (3).

$$
T=33302.91 v^{-1.8384} d^{-1}\left(59.42 w^{1.8486}-304.68 w^{0.8486}+440.4 w^{-0.1515}\right)
$$

where $T$ represents the screen's erosive puncture time, $\min ; v$ represents the fluid velocity, $\mathrm{m} / \mathrm{s} ; d$ represents the particle size, $\mu m$; and $w$ represents the concentration of sand-laden slurry, $\%$.

According to the prediction model given by Equation (3), a comparison was conducted between the experimental and theoretical results, which proved to be consistent with each other. Fig. 13 and Fig.14 show the results of the model predictions as well as the experimental results. It can be observed that the erosive failure time of the stars screen shows exponential relationship with flow velocity of sand-laden slurry and particle size. Moreover, it also decreases with the increase of sand-laden slurry's concentration. The erosive failure time of the stars screen in certain condition is matched by the model, with a maximum relative error of about $19.36 \%$ and an average relative error of about $9.48 \%$.

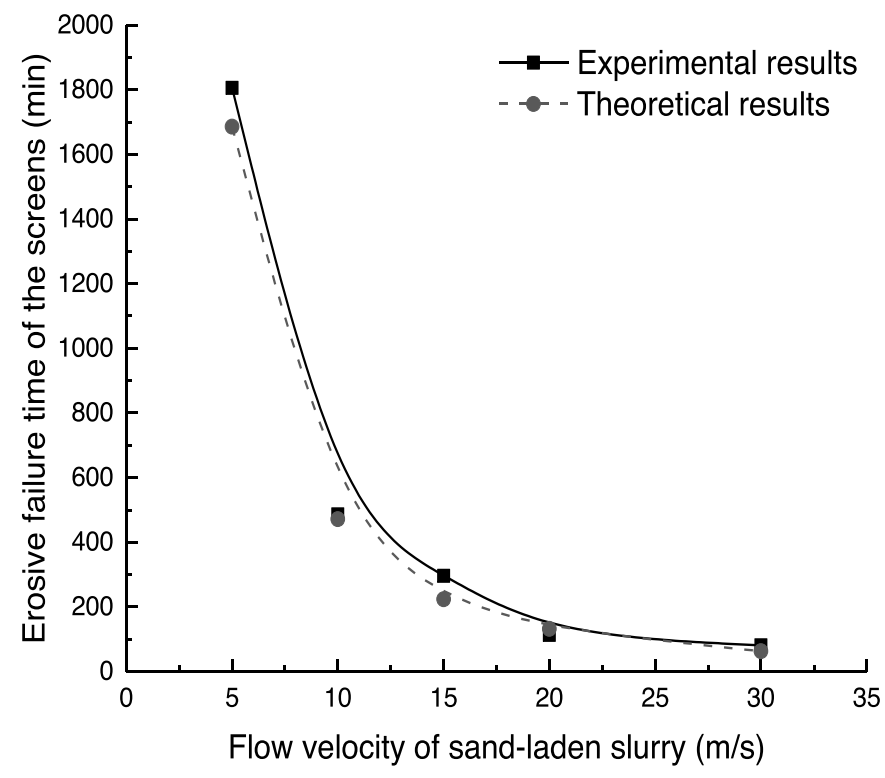

(a) Flow velocity of sand-laden slurry 


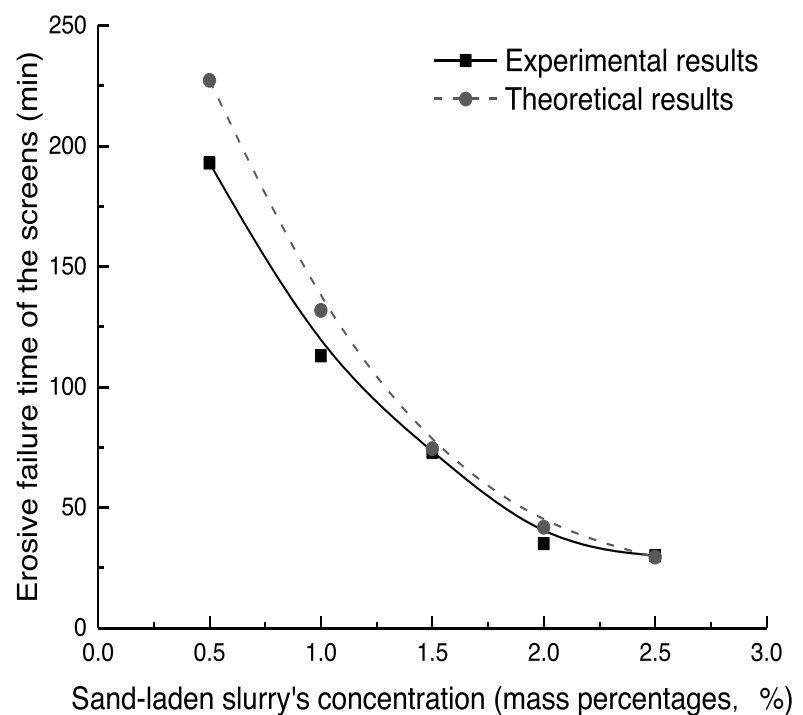

(b) Sand-laden slurry's concentration

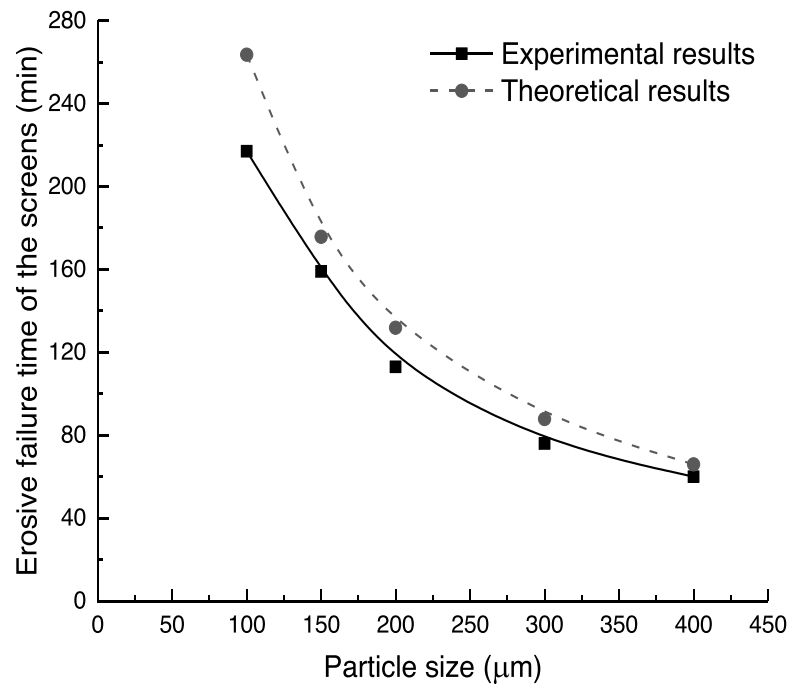

(c) Particle size

Fig. 14. Comparison between the experimental and theoretical results.

Under normal circumstances, the velocity of sand-laden slurry passing through a screen is relatively low, and the service-life of screens in oil and water wells usually lasts for several months or several years. Therefore, generally, it is impossible to simulate the failure of a screen with ground experiments over such a long period of time. However, according to the mathematical model established in Equation (3) and in combination with the actual underground working conditions and production parameters, an erosive failure time of screens can be obtained, which conformed to the flow velocity conditions of underground sand-laden slurry and, therefore, can predict the service-life of screens. Fig. 15 depicts the prediction curve for the change in erosive failure time of the stars screen with the sand-laden slurry velocity. With the increase in flow velocity, the erosive failure time reduced quickly. When the velocity was less than $5 \mathrm{~m} / \mathrm{s}$, the erosive failure time of the screen was especially sensitive to any change in the flow velocity. When the velocity was higher than $15 \mathrm{~m} / \mathrm{s}$, the erosive failure time of the screen basically remained unchanged and showed little difference in anti-erosion performance. In actual production process, due to the partial screen plugging, the flow 
velocity of the advantageous flow channel is increased. When the concentrations of sand-laden slurry, particle size, and flow velocity were $0.2 \%, 50 \mu \mathrm{m}$, and $1 \mathrm{~m} / \mathrm{s}$, respectively, the erosive puncture time of the stars screen was about $160 \mathrm{~d}$. When flow velocity reached $1.5 \mathrm{~m} / \mathrm{s}$, its erosive puncture time declined to $74 \mathrm{~d}$. Therefore, the fluid production velocity exerted a significant influence on the service-life of sand screens. In actual oilfield production, the status of screen plugging will be judged according to the changes in fluid production and the concentration of sand-laden slurry. Additionally, the partial plugging will be reduced by regulating the production of fluid or cleaning the shaft screen parts, which help control the velocity of sand-laden slurry passing through the screen's sand-retaining media, increase the service-life of screens, and lower the risk of sand production.

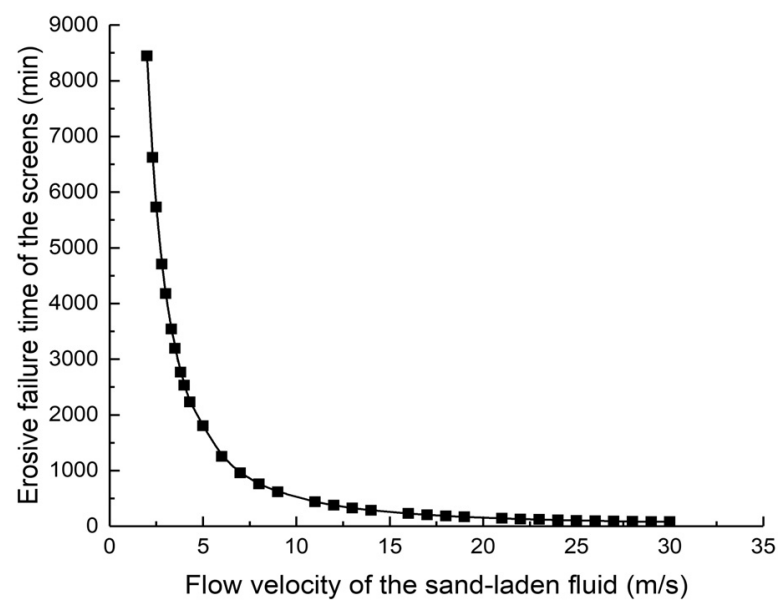

Fig. 15. Change in the erosive failure time of screens with the velocity of the sand-laden slurry.

\section{CONCLUSIONS}

The study proposes an experimental device, which can simulate the erosive failure of screens under simplified sand-control conditions. The device can be used to analyze the influence of sand-laden slurry flow velocity, sand particle size, sand-laden slurry's concentration, and erosive angle on screen's filtering medium's erosion and can provide some basis for determining the screen types, materials, sand-retaining medium structures, and productionrelated parameters.

The results showed that the sand-laden slurry velocity, sand-laden slurry's concentration, and sand particle size exerted an obvious influence on screen's erosion. Erosion of the screen's sand-retaining media by sand-laden slurry is the result of combined action of the deformation wear with a certain angular impact and the horizontal micro-cutting wear in surface contact with the metal wire material passing through the mesh. Different types of screens presented relatively significant differences in anti-erosion performance, and the anti-erosion performance of the stars screen was determined to be superior to that of the metal mesh screen.

Based on experimental data, this paper established a model for predicting the erosive failure time of the stars screen, which contained parameters such as the sand-laden slurry velocity, sand-laden slurry's concentration, and particle size. The model can be used to predict the service-life of screens in combination with the actual underground working conditions and production-related parameters. Last but not least, the sand-laden slurry velocity exerts a vital influence on the prediction of the well.

\section{ACKNOWLEDGMENT}

The authors express their appreciation to the supports from Open Foundation of China State Key Laboratory of Offshore Oil Exploitation (Grant No. CCL2015RCPS0229RNN), Natural Science Foundation of China (Grant No. 51274235). 


\section{REFERENCES}

Arabnejad H., Mansouri A. \& Shirazi S.A., et al., 2015. Development of mechanistic erosion equation for solid particles. Wear, 332-333:1044-1050.

Cameron J.A. \& Jones C., 2007. Development, verification, and application of a screen erosion model. SPE 107437.

Chen B., Zhang Q. \& Gong N., et al., 2019. Experimental Study on Erosion Wear of Sand Control Composite Screen in Water Source Wel. China Petroleum Machinery, 47(1):93-100.

Dong C., Zhang Q. \& Gao K., et al., 2016. Screen sand retaining precision optimization experiment and a new empirical design model. Petroleum Exploration and Development, 43(6): 991-996.

Dong C., Gao K. \& Dong S., et al., 2017. A new integrated method for comprehensive performance of mechanical sand control screens testing and evaluation. Journal of Petroleum Science and Engineering, 158: 775-783.

Finnie I., 1960. Erosion of surfaces by solid particles. Wear, 3(2):87-103

Finnie I., 1995. Some reflections on the past and future of erosion. Wear, S186-187(95):1-10.

Furui K., Fuh G. F. \& Morita N., 2011. Casing and screen failure analysis in highly compacting sandstone fields. SPE Drilling \& Completion, 27(2):241-252.

Gao H., Wang Z., Wang X. \& Wang D., 2017. Study on Friction Coefficient and Model of Astropyle Sand Control Screen. China Petroleum Machinery, 45(11):12-17.

Gillespie G., Beare S. \& Jones C., 2009. Sand control screen erosion when are you at risk?. SPE 122269.

Gillespie G. \& Jones C., 2009. Can sand-screen failures be prevented in gravel-packed cased-hole completions?. SPE 125170.

Hamid S. \& Ali S., 1997. Causes of sand control screen failures and their remedies. SPE 38190.

Islam M.A. \& Farhat Z., 2017. Erosion-corrosion mechanism and comparison of erosion-corrosion performance of API steels. Wear, 376-377:533-541.

Jackson S.R. \& Gundemoni B., 2016. Sand control in corrosive and erosive downhole conditions at high temperatures. SPE 182278.

Kanj M. Y. \& Abousleiman Y. N., 2007. Taming complexities of coupled geomechanics in rock testing: from assessing reservoir compaction to analyzing stability of expandable sand screens and solid tubulars. SPE Journal, 12(3), 293-304.

Lau H.C., Van Vliet J. \& Ward M., et al., 2004. Open-hole expandable-sand-screen completions in Brunei. SPE 87896.

Liu Y., Zhang J. \& Ma J., et al., 2009. Erosion wear behavior of slotted screen liner for sand control. Tribology, 29(03):283287.

Mahmoud A. \& Penny G., 2000. Sand control screen plugging and cleanup. SPE 64413.

Mnhmoud H.S. \& Ali A.M., 2015. Screen Erosion Guidelines for Sand Control Completion and Sand Production Management. Case Study West Delta Deep Marine (WDDM) Offshore Egypt. SPE 174739.

Navaira G., Hupp M.T. \& Palisch T.T., et al., 2009. A novel technique for determining sand screen failure. SPE 112084.

Narayanan C., Balz R. \& Weiss D.A., et al., 2013. Modelling of abrasive particle energy in water jet machining. Journal of Materials Processing Tech, 213(12):2201-2210.

Sidek S. \& Lian K.G.H., 2017. First successful application of ceramic sand screen in maturing oil field, offshore east Malaysia. SPE 188537.

Svela P.E., Gustavsen O. \& Solli H.S., 2009. Identifying point of failure and repairing damaged sand screens in gravel packed wells. A case history from the Heidrun Field. SPE 122153.

Tovar J. \& Zheng Y., 2011. Prediction and localization of erosion prone areas along non-compliant sand control completions. SPE 143164.

Zamberi M.S.A. \& Shaffee S.N.A., 2014. Reduced erosion of standalone sand screen completion using flow segmentizers. OTC 25019. 